In the opening days of 2009, people are looking for the new President Obama to restore domestic and international confidence and help us find our way out of a dark recession. Electric power generation and distribution is a key part of a new direction. Can we produce enough of it to reduce our oil usage? Can electric cars become reliable and cover enough distance on a single charge? Can its availability be increased, especially since critical services in transportation, banking, computing and many other sectors can be shut down by power grid failures?

In April 2000, Ubiquity Editor John Gehl spoke with energy expert Peter Huber about these issues. Huber's comments about the needs of the power grid were prophetic. We gladly bring them to you now in the hope that they will help you understand the power challenges ahead.

Peter Denning

Editor

\title{
An Interview with Peter Huber
}

\section{Why 99.9 Percent Is Not Good Enough}

Peter Huber predicts a dramatic rebuilding of the infrastructure. There is no acceptable level of downtime in the Information Age. Unprecedented demands on the electric power grid could leave you in the dark, or worse.

Peter Huber is co-editor of the Digital Power Report (Gilder Technology Group) and the author, most recently, of Hard Green: Saving the Environment from the Environmentalists (Basic Books 2000).

UBIQUITY: You've written that the power grid is "at the center of the new information economy." Why do you say that?

HUBER: It may be useful to start with an analogy. If I had said, a hundred years ago, "Look, oil is at the center of the new transportation economy," anybody who had bought a Model-T and was beginning to enjoy it would think, "Okay, I see. Oil isn't the Model-T, but it's the stuff that's needed to propel it." Well, today, electricity stands behind every bit that we move: microprocessors are just complex arrays of gates, capacitors and resistors; in fiber optics, you're using lasers, of course, to drive your information; and in the wireless arena, the third large domain of bits, you're propelling photons out into the ether. And behind every bit, behind every photon, stands a bucket of electrons. The electrons are the fuel. If the information age needs a fuel -- and indeed, it needs a lot of fuel -- that fuel is electricity.

UBIQUITY: But how do you see the electric grid as a problem that is new -- that has changed in nature?

HUBER: $\quad$ The grid we built up over the last hundred years was built for uses that, for the most part, were quite tolerant of outages and dirty power. Your current refrigerator doesn't really care at all if there's a twocycle hiccup in the power, as long as it's not so severe a hiccup that it fries the motor completely. If your lights go off for 15 minutes, it's usually something of a nuisance, but not much worse than that. The same goes for air conditioning: if it goes off for a day, that's unpleasant, but 15 minutes or half an hour -- most of the time, that's not a terrible a problem.

But in the information age, a new class of electrically powered systems stand at the center of everything. If you're America Online and your power goes off, you've stranded enormous numbers of people who are counting on your servers. If you're Schwab and your computers go down for an hour, you have an hour of time when people who subscribe to Schwab can't trade stocks. It's a very serious problem.

Of course, it isn't altogether new. Historically, hospitals, for example, couldn't lose their power even for a minute. You don't want your heart surgeon in the dark, even for 60 seconds. And phone companies have long had their own backup power systems for similar reasons. The lights went out, but the phones stayed on because people needed their 911 and other links to the world even if they didn't have their lights. Especially when they didn't have their lights. What we're now finding is that electricity has become equally "mission-critical," to a much broader range of day-to-day activities. 
You lose the power behind the sprawling array of microprocessors that surrounds you -- and you're really stranded.

UBIQUITY: Just how reliable or unreliable is the existing power grid?

HUBER: It's remarkably reliable -- but only by yesterday's standards. You're typically looking at perhaps eight or ten hours a year of gross outages, for a typical customer on the grid. And in terms of hiccups -where the power is at 60 cycles a second, but you drop a cycle or two when your neighbor turns on a welder or something like that -- you're typically looking at one hiccup every few hours. All of that is pretty good -- by yesterday's standards. But a two-cycle hiccup can reboot all of your computers! If you doubt that, just try running your computers for a week without a surge suppresser. And outages of any length at all, from minutes on out, are simply intolerable for most offices today, as well as most factories, insofar as they're highly dependent on the information infrastructure. That includes all of the "dot-coms," of course, and all of the banks, and in fact the entire digital economy. And equally intolerable for a rapidly increasing number of wired, digital homes.

UBIQUITY: Can you quantify the power grid's level of reliability?

HUBER: $\quad$ The standard engineering measure for these things is in terms of nines -- low nines, high nines. Very roughly speaking, the grid we're accustomed to offers about three or four nines power, where three nines means $99.9 \%$ reliable, four nines means $99.99 \%$ reliable, and so forth. We're talking about, on a year-round basis, outages in the range of hours per year, and that comes down to about three, perhaps four, nines.

For the microprocessor and everything that surrounds it -- which would include the wireless radios and the fiber optic systems and the modems and so on -- you really can't abide hiccups that last more than a fraction of a cycle. This means that hiccups that are more than a few milliseconds are very bad indeed, and outages of minutes or days can be simply catastrophic if you're doing anything other than just browsing the Web very casually in the late evening, or engaging in the most idle chat. If you're doing serious work, you're really looking for very high nines' power. You're insisting on six nines or more power -- outages of literally no more than fractions of a millisecond on a day-to-day basis and really no more than minutes a year, if that.

UBIQUITY: So three nines reliability would translate into roughly how many hours of down time?

HUBER: Well, it's about eight hours a year, if you're running 24 hours a day. How that eight-hour period is spread out matters a lot as well. If it spreads out as three dropped cycles every hour, that means crashing your computer every hour, unless you've got something in between the grid and your microprocessor to clean things up. And just about any of us would go nuts these days if our computer were rebooting even several times a day at random intervals. That's why all serious computer users are already investing heavily -- at the very least in surge protectors and desktop backup power systems -- to clean up those millisecond hiccups that are extremely common in the backbone grid but quite intolerable once you get very close to your computer.

UBIQUITY: So what is the answer?

HUBER: Over time, I think what we're going to see is a massive and very fundamental reengineering of the power grid. It's not that the old systems are just going to be junked or thrown away -- the existing grid represents a huge and still very valuable infrastructure. What we will see is a dramatic process of rebuilding and adding to it, from the bottom up. Most of us have already started this process, in that most users already have on their desktop their own little power company -- at the very least, a surge protector, and more likely a small backup uninterruptible power supply -- UPS. That at least gives us a clean, orderly shutdown when the lights go out.

A rapidly growing number of offices, all so-called "dot-com" hotels, and all medium-size and larger "dot-coms," are now putting larger power generating systems of one kind or another on their premises. These range from large standby battery systems or flywheels -- they're called ride- 
through systems -- which can smooth out briefer interruptions, from seconds to minutes.

Then there are on premises fuel cells, which you will use if you're in the center of a city and you can't deploy anything else. Fuel cells are expensive, but they also run very clean. Standby diesel (gas or liquid fuel) generator sets are used in much greater numbers in office buildings and, increasingly, in homes too, as backup systems. And on up the grid, power providers and larger users are rapidly deploying redundant, short-wire sources of power.

UBIQUITY: And all this amounts to -- ?

HUBER: A progressive, but fundamental, reengineering of the architecture of the grid -- the power grid itself begins to mirror the architecture of the Web! The Web dispersed the computing power out of the mainframe. Now it drags the grid along behind it, decentralizing and dispersing the electrical supply.

UBIQUITY: You've written about the contrast between the smart chip and the power chip. Tell us about that.

HUBER: That's a very interesting component of the story. It comes down to this: Introducing all these new power components into the grid is not sufficient on its own. You can stick a diesel generator set outside your factory or "dot-com" and you can have a backup battery system and a flywheel and so on -- all very nice, but to make them useful you have to be able to switch between them on the fly, as needed, and switch between these seamlessly. If you can't do that, the very process of switching from one to the next will cause more problems than it solves. When you go offline on the grid and turn on a diesel generator set or flip between that generator and a flywheel connected to a ridethrough generator, that switching process itself creates new power spikes and new ripples and noise all the way through the system. Without the right switches, your "solution" can be as bad as, or worse than, your problem.

UBIQUITY: So what's the cure?

HUBER: The cure, in a nutshell, is to have extremely fast, solid-state switches at the all the points where you need them. If you can flip very quickly between different sources of standby power and grid power, you can achieve your ultimate objective, which is to obtain very steady, smooth power where you want it, at your digital processors and radios and fiber-optic lasers.

But here's the problem: making switches switch very quickly is difficult, at least in the old, electromechanical world of switching. A light switch is a slow, dirty switch, electrically speaking. When you go further up the grid and get big electromechanical switches they tend to add huge amounts of new noise to the grid.

The way around this problem is to go solid state. Roughly speaking, the same solid-state materials that are being used to create the switches that define the logic gates in a microprocessor, at nanowatt levels, can be -- and are being built -- to perform power-switching functions at the kilowatt and megawatt level.

UBIQUITY: And this is a straightforward process?

HUBER: $\quad$ Not at all. There are major engineering challenges involved. But basically you can take silicon -- or eventually, silicon-carbide and other semiconductor materials, and instead of painting millions of logic gates on it and turning it into a Pentium, you paint a single gate onto it and make it a power switch. I'm simplifying the engineering a lot, but that's what it comes down to. You make your wafer behave as a single gate, but one that can handle a lot of power. With switches like that, you can then do the very fast switchovers between different sources of electrical power. And those fast switchovers are the key to having very clean power out the other end.

Inside the UPS that sits on your desktop, you'll find more electronics than battery, not more pounds worth, but more dollars worth. A whole motherboard of electronics whose whole function is to switch, as needed, between the dirty power on the grid and the backup power in the battery. 
UBIQUITY: Who's making these power chips?

HUBER: There is a whole range of companies, but since I co-edit an investment newsletter on this, I'll just invite interested persons to consider taking a subscription to our newsletter. It's the Digital Power Report. My co-editor is Mark Mills.

UBIQUITY: Who is the publisher?

HUBER: It's published by the Gilder Technology Group, George Gilder's publishing enterprise. George publishes his Telecosm newsletter, and my colleague Mark Mills and I have just started up a parallel investment letter addressing the issues that we've been discussing. The Digital Power Report discusses the whole gamut of these companies, from the chip manufacturers, through the fuel cells and the diesel gen-sets and on up the power curve.

UBIQUITY: Can you give us a general idea of just how large or small the industry segment is?

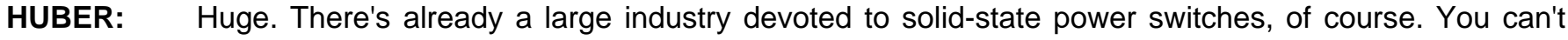
buy a stereo, cell phone, or computer without a power switch on the board. But those tend to be quite low power devices. The higher you move up the power curve, the closer you get to state-of-the-art technology, just now coming of age in the marketplace.

A very wide range of manufacturers is involved. And there are strong overlaps between the exploding world of the microprocessor and the now emerging world of silicon power technology. Many of the raw materials and wafer-fab and etching methods and facilities are common to both industries.

UBIQUITY: Is it fair to assume that you believe that the power chip represents a great investment opportunity?

HUBER: As in any other field, the difference between a great investment opportunity and a crummy one is picking the right companies. But, to my mind, the general paradigm I've outlined is has to be right. The faster we move into an economy that is highly dependent on intelligent, solid state microprocessors, lasers, and radios -- and, as everybody knows, we are moving, at breakneck speed into that economy -- the faster we will find demand rising for the systems that provide electrical "fuel" of the quality that that economy requires.

UBIQUITY: Which brings us back to the start of this conversation and your analogy with oil in the age of the automobile.

HUBER: Exactly. It's tantamount to saying, "Look, if we're going to move into the auto age and people are going to move from the Model-T to the Porsche over the next year or decade or half century -whatever timeframe you care to choose -- over that same timeframe, they will need the fuel to go with it. The digital telecosm requires for its fuel electrons of a very different quality than is delivered by yesterday's grid. So different that we're talking about a really major rebuild of the infrastructure.

UBIQUITY: Sounds like a good investment.

HUBER: Yes. Unless of course you think we've peaked or are actually going to scale back on investment in microprocessors and digital technologies. If you believe that -- I certainly don't -- then, of course, this is a crummy investment.

UBIQUITY: When and how did you get interested in this particular problem?

HUBER: $\quad$ My colleague Mark Mills and I have been writing about this on and off for quite some time. As with so many issues, some of my interest can be traced to hard experience. Like countless other power users and people who try to run offices, I've been repeatedly frustrated by the simple problem of how to keep PCs and networks up and running in the face of unreliable power. Last winter, during an ice storm, I was without power for three days in my suburb of Washington, DC. Five years ago that would have been a real nuisance. Last winter it was a disaster. I had to yank up my hardware and relocate it. Huge numbers of other people in the country -- from the residence level up to the office and "dot- 
com" levels -- are now facing similar challenges. One way or another, they're going to address them.

UBIQUITY: You have quite an accomplished background; tell us a little bit about yourself.

HUBER: I was trained as a mechanical engineer at MIT and got my doctorate there and then taught there, as an assistant and later associate professor, for six years. Along the way I got a law degree, and clerked for a couple of years for then-Judge (now Justice) Ruth Bader-Ginsburg and then for Justice Sandra Day O'Connor. Since then, I've been writing about issues at the intersection of technology and public policy and law. I also write a column for Forbes magazine on these subjects. And then most recently I've begun co-editing the monthly Digital Power Report for the Gilder Technology Group.

UBIQUITY: Well, this would be a perfect place to tell any Ubiquity readers interested that they can find all your reports on power, and on other subjects as well, at your website, http://www.manhattaninstitute.org/html/huber.htm.

Thank you for talking with us today! 